\title{
Stern Lessons on Climate Change: Stabilisation Targets and Emission Reductions
}

\author{
Jonathan Boston
}

\section{Introduction}

In mid-2005 the British government commissioned its chief economic adviser, Sir Nicholas Stern, to review the economics of climate change. His report, released in late October 2006, is detailed, comprehensive and sobering. Not surprisingly, given the many controversies surrounding the causes and likely consequences of climate change, the report has sparked vigorous debate. Predictably, various critics have questioned key elements of the scientific evidence upon which the Stern Review is based (see Carter, et al., 2006; Lawson, 2006). Others have challenged some of the main assumptions underpinning the Review's economic analysis, such as the use of a very low discount rate, the focus on total costs and benefits rather than marginal costs and benefits, and the claimed tendency to rely on the most pessimistic studies and estimates of the damage that global warming may cause (see Lomborg, 2006; Nordhaus, 2006; Tol, 2006). ${ }^{1}$ For such reasons, it is argued that the Review is likely to have overestimated the environmental, social and economic impacts of climate change, and thus exaggerated the expected benefits of measures to reduce greenhouse gas (GHG) emissions.

Against this, others maintain that the Review underestimates the potential costs and risks of climate change, including the scope and scale of damages likely to be caused at different temperatures and the risks of abrupt climate change (see Stern, 2006b, p.2, and the Technical Annex, p.4). A related concern is that the Review endorses a stabilisation target for GHG concentrations in the atmosphere that, given the cost-benefit estimates reported, is insufficiently stringent (Baer, 2007; Tol and Yohe, 2006), and

1 The issues surrounding the discount rate used by Stern are explored by Dennis Rose in a separate article in this issue of Policy Quarterly. arguably incompatible with the requirements of the United Nations Framework Convention on Climate Change (UNFCCC). Under article 2 of this Convention, the parties agreed to ensure that GHG concentrations would be stabilised at a level that prevents 'dangerous anthropogenic interference with the climate system'. Stabilisation targets of the kind proposed by Stern, it is argued, are likely to result in an increase in the global mean surface temperature, at equilibrium, of around $3^{\circ} \mathrm{C}$ (i.e. above pre-industrial levels). This is well above the cap of $2^{\circ} \mathrm{C}$ of warming which has been endorsed by many scientists and the European Union (EU) as being the maximum compatible with the provisions of the UNFCCC. Indeed, Stern readily accepts that the upper end of the Review's proposed stabilisation target range is a 'risky place to be' (2006b, p.3).

The purpose of this brief article is to consider some of the key issues surrounding stabilisation targets. These include the relationship between GHG concentrations in the atmosphere and changes in global mean surface temperatures, the necessary conditions for achieving a stabilisation of GHG concentrations, the magnitude of the GHG emission reductions required to meet particular stabilisation targets, and the reasoning behind the targets proposed by the Stern Review. It must be emphasised that the issues surrounding stabilisation targets are complex and it is only possible to provide a broad summary of the relevant considerations in this article. Furthermore, there are many remaining uncertainties, knowledge gaps and areas of continuing debate, particularly in relation to climate sensitivity, the operation of various feedback mechanisms and the degree of inertia in the climate system. For such reasons, there is a need for caution and humility in addressing the question of what stabilisation target(s) might be appropriate. 


\section{Stabilisation levels and temperature increases}

In 2006 the concentration of $\mathrm{CO}_{2}$ in the atmosphere reached 380 parts per million (ppm), or around 35\% above pre-industrial levels. During the past decade, concentrations have been rising at close to $2 \mathrm{ppm}$ per annum, and the rate of increase has accelerated somewhat since the 1960s and 1970s. Taking the six Kyoto GHGs into account $\left(\mathrm{CO}_{2}, \mathrm{CH}_{4}, \mathrm{~N}_{2} \mathrm{O}, \mathrm{SF}_{6}\right.$, HFCs and PFCs), the Stern Review (2006a, p.193) estimates that the concentration of GHGs is presently around $430 \mathrm{ppm}$ $\mathrm{CO}_{2}$ equivalent $\left(\mathrm{CO}_{2} \mathrm{e}\right)$. This is close to $50 \%$ higher than pre-industrial levels. On a plausible business-as-usual scenario, it is estimated that $\mathrm{CO}_{2} \mathrm{e}$ concentations will reach 550 ppm by 2035 , and much higher levels later in the century (Stern, 2006a, p.177). ${ }^{2}$

Uncertainty remains over the sensitivity of the climate to increasing concentrations of GHGs in the atmosphere. (The climate sensitivity is defined as the increase in the global mean surface temperature, at equilibrium, as a result of a sustained doubling of $\mathrm{CO}_{2}$ concentrations.) Hence, as the Stern Review (2006a, p.194) readily acknowledges, 'The relationship between stabilisation levels and temperature rise is not known precisely'. Nevertheless, for over two decades there has been a broad consensus that the climate sensitivity is very likely to fall between $1.5^{\circ} \mathrm{C}$ and $4.5^{\circ} \mathrm{C}$, with only a small chance (e.g. around $5-10 \%$ ) of a rise of a lesser or greater amount. ${ }^{3}$ The consensus view is based on evidence from a range of sources, including simulations using global climate models, analysis of the impact of specific events (such as the eruption of Mt Pinatubo in 1991) on global temperatures, assessment of paleo-climate data, and analyses based on observed temperature changes since the mid-19th century. Thus far, most of the analyses have yielded a skewed climate sensitivity probability distribution - with a longer tail on the higher end of the temperature spectrum.

2 Carter et al. (2006, p.197) dispute the proposition that $\mathrm{CO}_{2} \mathrm{e}$ concentrations in the atmosphere will increase by as much as 120 ppm by 2035 , but given various assumptions (e.g. continued global economic growth, limited action to reduce greenhouse gas emissions, etc.) there can be little doubt that concentrations will continue to increase and are likely to do so at an accelerating rate.

3 According to the recently published 'Summary for Policymakers' of the IPCC's Fourth Assessment Report, climate sensitivity 'is likely to be in the range of 2 to $4.5^{\circ} \mathrm{C}$ with a best estimate of about $3^{\circ} \mathrm{C}$ ' $(2007$, p.12)
Some very recent analyses have pointed to the climate sensitivity being slightly higher than estimated in the 1990s. Such results reflect, in part, the placing of rather greater weight on the impact of various amplifying feedbacks, such as the release of methane from melting permafrost in the Arctic and the weakening of major carbon sinks (e.g. the Amazon rainforest) (see Steffen, 2006). Nevertheless, most estimates suggest that a sustained doubling of $\mathrm{CO}_{2}$ concentrations from preindustrial levels (to around $550 \mathrm{ppm}$ ) can be expected (other things being equal) to generate an increase in the global mean surface temperature of approximately $3^{\circ} \mathrm{C}$ at equilibrium. Note that equilibrium levels will not be achieved for well over a century.

But what magnitude of temperature increase might be expected if $\mathrm{CO}_{2}$ concentrations are stabilised at levels lower (or higher) than $550 \mathrm{ppm}$, and what are the risks of an increase of more than $3^{\circ} \mathrm{C}$ if concentrations double? Table 1, which is drawn from the Stern Review, outlines an indicative range of likelihoods of exceeding a certain increase in temperature, at equilibrium, for a series of stabilisation levels measured in $\mathrm{CO}_{2}$ e. The 'maximum' and 'minimum' columns show the maximum and minimum chance of exceeding a particular temperature increase, based on 11 recent studies (see Meinshausen, 2006). The results reported for the 'Hadley Centre' in Table 1 are based on Murphy et al. (2004), while the results of the 'IPCC TAR 2001' (Intergovernmental Panel on Climate Change, Third Assessment Report) are based on Wigley and Raper (2001). Note that the individual values are approximate only.

The data presented in Table 1 highlight a number of significant points. First, the Hadley Centre's results reflect the incorporation of slightly higher climate sensitivity estimates than those used by the IPCC in 2001. It is notable that only a modest increase in such estimates generates a relative large rise in the probability of exceeding particular temperature thresholds. Second, it is interesting to consider the implications if $\mathrm{CO}_{2} \mathrm{e}$ concentrations were to be stabilised at $450 \mathrm{ppm}$ - which is only about $20 \mathrm{ppm}$ above current levels. Based on the results in the 'minimum' column, there is at least a $26 \%$ chance of the global mean surface temperature rising by more than $2^{\circ} \mathrm{C}$, and a $4 \%$ chance of it exceeding $3^{\circ} \mathrm{C}$. At the other extreme (i.e. using the results in the 'maximum' column), there is a $78 \%$ chance of exceeding $2^{\circ} \mathrm{C}$, a $50 \%$ chance of exceeding $3^{\circ} \mathrm{C}$ and even a $21 \%$ 
Table 1: Likelihood of exceeding a temperature increase at equilibrium

\begin{tabular}{|c|c|c|c|c|}
\hline $\begin{array}{l}\text { Stabilisation level } \\
\left(\mathrm{CO}_{2} \mathrm{e}\right)\end{array}$ & Maximum & $\begin{array}{l}\text { Hadley Centre } \\
\text { Ensemble }\end{array}$ & $\begin{array}{l}\text { IPCC TAR 2001* } \\
\text { Ensemble }\end{array}$ & Minimum \\
\hline \multicolumn{5}{|c|}{ Probability of exceeding $2^{\circ} \mathrm{C}$ (relative to pre-industrial levels) } \\
\hline 400 & $57 \%$ & $33 \%$ & $13 \%$ & $8 \%$ \\
\hline 450 & $78 \%$ & $78 \%$ & $38 \%$ & $26 \%$ \\
\hline 500 & $96 \%$ & $96 \%$ & $61 \%$ & $48 \%$ \\
\hline 550 & $99 \%$ & $99 \%$ & $77 \%$ & $63 \%$ \\
\hline 650 & $100 \%$ & $100 \%$ & $92 \%$ & $82 \%$ \\
\hline 750 & $100 \%$ & $100 \%$ & $97 \%$ & $90 \%$ \\
\hline \multicolumn{5}{|c|}{ Probability of exceeding $3^{\circ} \mathrm{C}$ (relative to pre-industrial levels) } \\
\hline 400 & $34 \%$ & $3 \%$ & $1 \%$ & $1 \%$ \\
\hline 450 & $50 \%$ & $18 \%$ & $6 \%$ & $4 \%$ \\
\hline 500 & $61 \%$ & $44 \%$ & $18 \%$ & $11 \%$ \\
\hline 550 & $69 \%$ & $69 \%$ & $32 \%$ & $21 \%$ \\
\hline 650 & $94 \%$ & $94 \%$ & $57 \%$ & $44 \%$ \\
\hline 750 & $99 \%$ & $99 \%$ & $74 \%$ & $60 \%$ \\
\hline \multicolumn{5}{|c|}{ Probability of exceeding $4^{\circ} \mathrm{C}$ (relative to pre-industrial levels) } \\
\hline 400 & $17 \%$ & $1 \%$ & $0 \%$ & $0 \%$ \\
\hline 450 & $34 \%$ & $3 \%$ & $1 \%$ & $0 \%$ \\
\hline 500 & $45 \%$ & $11 \%$ & $4 \%$ & $2 \%$ \\
\hline 550 & $53 \%$ & $24 \%$ & $9 \%$ & $6 \%$ \\
\hline 650 & $66 \%$ & $58 \%$ & $25 \%$ & $16 \%$ \\
\hline 750 & $82 \%$ & $82 \%$ & $41 \%$ & $29 \%$ \\
\hline \multicolumn{5}{|c|}{ Probability of exceeding $5^{\circ} \mathrm{C}$ (relative to pre-industrial levels) } \\
\hline 400 & $3 \%$ & $0 \%$ & $0 \%$ & $0 \%$ \\
\hline 450 & $21 \%$ & $1 \%$ & $0 \%$ & $0 \%$ \\
\hline 500 & $32 \%$ & $3 \%$ & $1 \%$ & $0 \%$ \\
\hline 550 & $41 \%$ & $7 \%$ & $2 \%$ & $1 \%$ \\
\hline 650 & $53 \%$ & $24 \%$ & $9 \%$ & $5 \%$ \\
\hline 750 & $62 \%$ & $47 \%$ & $19 \%$ & $11 \%$ \\
\hline
\end{tabular}

* Intergovernmental Panel on Climate Change, Third Assessment Report, 2001.

Source: Stern Review, 2006a, p.195.

chance of a huge $5^{\circ} \mathrm{C}$ temperature increase. Third, if $\mathrm{CO}_{2} \mathrm{e}$ concentrations exceed $550 \mathrm{ppm}$ for an extended period, there is only a small chance $(37 \%$ on the most optimistic estimate and 1\% using the Hadley results) of staying within the European Union's proposed $2^{\circ} \mathrm{C}$ cap, and around a $30-70 \%$ chance of exceeding $3^{\circ} \mathrm{C}$. Finally, even stabilising $\mathrm{CO}_{2} \mathrm{e}$ concentrations at 400 ppm generates a significant risk $(13 \%$ for the IPCC
TAR and 33\% for Hadley) of a temperature increase of more than $2^{\circ} \mathrm{C}$, and there is even a small risk of exceeding $4^{\circ} \mathrm{C}$. Put differently, as Meinshausen (2006, p.264) has observed, 'Only at levels around 400ppm $\mathrm{CO}_{2}$ equivalent or below, could the probability of staying below $2^{\circ} \mathrm{C}$ in equilibrium be termed "likely" for most of the climate sensitivity PDFs [probability density functions]'. 
How concerning are such results? If the probability ranges reported in Table 1 are broadly correct (and this, admittedly, remains open to some debate), the results present a stark warning. After all, an increase in the global mean surface temperature of $2^{\circ}-3^{\circ} \mathrm{C}$ will have very significant, and largely negative, environmental, social and economic impacts across the globe. As summarised in the Stern Review and elsewhere (Chapman et al., 2006; Schellnhuber et al., 2006), such impacts include an increase in the sea level of many metres, more severe droughts, floods and storms, the loss of most coral reefs and mountain glaciers, and the extinction of a significant proportion of terrestrial species. Such changes will generate major water shortages in many regions, reduce food production, inundate many coastal settlements and river deltas, and cause huge economic losses. Quite apart from this, sustained high concentrations of GHGs in the atmosphere are likely to have major adverse impacts on oceanic chemistry and marine ecosystems (Turley, 2006).

\section{Achieving stabilisation}

In order to stabilise $\mathrm{CO}_{2}$ e concentrations, it will be necessary for global GHG emissions to equal the natural uptake of carbon from the atmosphere. As the Stern Review (2006a, p.194) points out:

The longer global emissions remain above this level, the higher the stabilisation level will be. It is the cumulative emissions of greenhouse gases, less their cumulative removal from the atmosphere, for example by chemical processes or through absorption by the Earth's natural systems, that defines their concentration at stabilisation.

Bear in mind that the natural rate of uptake is at least partly influenced by human actions, such as deforestation, afforestation and other land-use changes. Globally, significant deforestation is occurring, thus reducing the natural uptake of carbon. Achieving stabilisation, therefore, will require action not only to reduce GHG emissions but also to increase carbon sequestration into the biosphere via land-use changes (such as afforestation and reforestation). In developing a global mitigation strategy, the question of the appropriate balance between emission reductions and land-use changes is one of many issues that deserve further attention (see Read, 2006).
On the basis of the estimated current natural uptake of carbon, achieving stabilisation - at whatever the agreed concentration of $\mathrm{CO}_{2} \mathrm{e}-$ will require emission reductions of at least $80 \%$ from 2005 levels (Stern, 2006a, p.199). What this means for individual countries will depend on a range of technical, ethical and political considerations. In all likelihood, richer countries with high per capita emissions will be expected to reduce their emissions by more than the average. This could well entail net emission cuts of over $90 \%$ from current levels (with the precise reduction in gross emissions dependent upon the potential for securing offsets).

Other things being equal, the timeframe within which stabilisation occurs, and the eventual stabilisation level that is secured, will depend on how rapidly emissions can be cut. Realistically, of course, any global effort to stabilise $\mathrm{CO}_{2}$ e concentrations is likely to take much of this century to achieve. Leaving aside the cumbersome and time-consuming nature of global negotiations over climate-change policy, there is substantial inertia in the global economy, with the result that it will take considerable time and effort to move towards a lowemissions pathway. This is due to lengthy infrastructure investment processes and long replacement cycles for most capital stock, as well as the sheer magnitude of the task of decarbonising complex and expensive energy and transportation systems (e.g. replacing carbon-intensive capital stock with low-carbon technologies). Equally, the Earth's climate system is characterised by considerable lags. Hence, even if GHG emissions are stabilised and then reduced rapidly over the next few decades (which will be a significant challenge), $\mathrm{CO}_{2}$ e concentrations will take many decades to stabilise, the global mean surface temperature will continue to rise for a much longer period, and the sea level is likely to continue rising for several thousand years.

Importantly, too, there is some uncertainty over the likely natural uptake of carbon during the coming century, and in particular over whether changes in the climate will increase or reduce the natural absorption rate. At this juncture, the available evidence suggests that there is a significant risk that the absorption of $\mathrm{CO}_{2}$ by the Earth's soils, vegetation and oceans will slow as the mean temperature increases. If this is the case, then even greater reductions in cumulative emissions (and/or expansion of carbon sinks) will be required to achieve any particular stabilisation target. Furthermore, 
after stabilisation has been achieved it is expected that the level of natural absorption will fall, partly because of the gradual exhaustion of the vegetation sink and partly because of a weakening of the rate of ocean uptake (Stern, 2006a, p.197). Given this situation, GHG emissions will need to keep falling long after stabilisation has been achieved. Indeed, according to the Stern Review, it may be necessary in the long run to reduce annual emissions to less than $1 \mathrm{GtCO}_{2} \mathrm{e}$ (gigatonnes of $\mathrm{CO}_{2} \mathrm{e}$ ) in order to maintain a particular stabilisation level. This would mean cutting emissions to about $2 \%$ of current levels - which are close to $45 \mathrm{GtCO}_{2}$ e per annum.

As the Stern Review observes, there is a distinction between 'stabilisation' and 'peaking'. Conceptually, it might be possible for $\mathrm{CO}_{2}$ e concentrations to peak at, say, $470 \mathrm{ppm}$ and then fall gradually, via an effective mitigation strategy, to an intended stabilisation level of, say, $450 \mathrm{ppm}$. This, however, would require reducing annual emissions below the natural absorption rate for a significant period of time or, alternatively, raising the natural absorption rate 'artificially' for a period through extensive afforestation and reforestation. But such approaches may be very hard to implement, for technical and/or political reasons. Moreover, as highlighted by Meinshausen (2006), the level of the peak, the magnitude of the 'overshooting', and the length of time near the peak are likely to be important - and there is always the risk that the natural rate of carbon absorption may weaken under the impact of higher temperatures and related feedback processes, thus making it all the more difficult to reach the intended stabilisation target. For such reasons, the Stern Review cautions against placing too much reliance upon the idea of overshooting as part of a global mitigation strategy.

\section{Setting stabilisation targets}

Stern recommends a stabilisation target of between 450 and $550 \mathrm{ppm} \mathrm{CO}_{2} \mathrm{e}$. This is in line with the recommendations of various scientists, such as Barrie Pittock (2006, p.292). The logic for this particular target range is summarised in the Review as follows:

stabilisation at levels below $450 \mathrm{ppm} \mathrm{CO}_{2} \mathrm{e}$ would require immediate, substantial and rapid cuts in emissions that are likely to be extremely costly, whereas stabilisation above 550 ppm $\mathrm{CO}_{2}$ e would imply climatic risks that are very large and likely to be generally viewed as unacceptable.

There can be little doubt, given the sobering evidence presented by Stern, that a stabilisation target above 550 ppm $\mathrm{CO}_{2}$ e would be unacceptably high - on a range of ethical, environmental and economic criteria. A target of $650 \mathrm{ppm}$, for instance, would almost certainly result in a mean temperature increase of more than $2^{\circ} \mathrm{C}$ and would have a relatively high chance of generating an increase of more than $3^{\circ} \mathrm{C}$. But is not a target range of 500-550 ppm $\mathrm{CO}_{2}$ e also unacceptable? After all, on the Hadley Centre's estimates, stabilisation at 500 ppm yields a $96 \%$ chance of exceeding $2^{\circ} \mathrm{C}$ and a $44 \%$ chance of exceeding $3^{\circ} \mathrm{C}$. By almost any standards these are high risks. And, as previously noted, a mean temperature increase of these magnitudes will have serious and pervasive impacts on ecosystems, physical infrastructure, food production, geopolitical stability and human well-being - and many of the impacts will be irreversible.

Yet, as the Stern Review highlights, achieving a stabilisation level of $500 \mathrm{ppm} \mathrm{CO}_{2} \mathrm{e}$, let alone a lower figure, will be a formidable undertaking. Table 2 illustrates the emission paths required to reach three different stabilisation targets: $450 \mathrm{ppm}, 500 \mathrm{ppm}$ and $550 \mathrm{ppm} \mathrm{CO}_{2}$ e. As shown in the Table, to have any realistic chance of stabilising at $450 \mathrm{ppm} \mathrm{CO}_{2} \mathrm{e}$, global GHG emissions must peak no later than around 2010 and then fall at a rate of about $7 \%$ per annum, with an overall cut in emissions of about $70 \%$ below 2005 levels by 2050. According to Stern (2006a, p.193), such rapid, sustained cuts may be unachievable given existing and readily foreseeable technologies (and assuming continuing global economic growth). Stabilising at 500 ppm $\mathrm{CO}_{2} \mathrm{e}$ is somewhat less taxing, but nevertheless emissions will need to peak no later than around 2020 (to avoid overshooting), and then fall at around 4-6\% per annum, with a decrease of $60-70 \%$ by 2050 . Such rates of reduction are outside the parameters of what has been achieved thus far in individual states (let alone at the global level), except during periods of serious political and economic upheaval. Even to achieve a stabilisation target of $550 \mathrm{ppm} \mathrm{CO}_{2}$ e will be challenging. As Stern (2006a, p.205) notes, this is likely to require cutting current global average emissions per capita by $50 \%$ by 2050 , and an even larger reduction in emissions per unit of GDP. 
The results presented in Table 2 also highlight the importance of early policy action: the longer that effective measures to curb emissions are delayed, the more substantial the reductions will need to be to meet a particular target. For instance, a delay of even ten years in the date at which emissions peak is likely to mean that emissions will have to fall at a $50-100 \%$ faster rate to achieve the agreed target. Moreover, delayed action increases the risks of severe climate impacts and accentuates the potential for triggering abrupt changes in the climate system.

Policy action to stabilise and then reduce emissions in a sustained manner will impose costs - although the magnitude of these should not be exaggerated. Using various methodologies, Stern (2006a, p.xiv) estimates that stabilising $\mathrm{CO}_{2} \mathrm{e}$ concentrations at $500-550 \mathrm{ppm}$ will cost about $1 \%$ of annual global GDP by 2050 (with a range of between $-5 \%$ and $+1 \%$ of GDP). In other words, global GDP will be about 1\% lower midcentury than it would have been had there been no mitigation strategy in place. Assuming a global GDP of about US $\$ 100$ trillion in 2050 , the cost would be about US\$1 trillion - not a trivial sum, but less than twice what the US currently spends each year on defence (including the 'Global War on Terror'). Beyond 2050 the costs of mitigation are much less certain; but they may well increase if - as might be expected - it becomes necessary to make greater use of the more expensive low-carbon technologies that are available. Overall, Stern's calculations are consistent with much of the recent literature on the costs of decarbonising the global economy (see Hatfield-Dodds, 2006; Metz and van Vuuren, 2006), and are therefore likely to concur with the conclusions of the forthcoming Fourth Assessment Report of the IPCC (Stern, 2006b, p.3).

To date, relatively few studies have examined the technical feasibility and likely costs of achieving a $\mathrm{CO}_{2} \mathrm{e}$ stabilisation target at the lower end of Stern's proposed range (i.e. $450 \mathrm{ppm}$ ). Such analyses suggest, however, that the costs will be greater than those associated with the pursuit of a target of $550 \mathrm{ppm}$ - perhaps as much as three times higher (Stern, 2006a, p.247). One reason for this is that a lower target will necessitate very sharp reductions in emissions within the next few decades, thus entailing the premature retirement of carbonintensive capital stock, retrofitting cleaner technologies

Table 2: Illustrative emission paths to stabilisation

\begin{tabular}{|c|c|c|c|c|}
\hline \multirow[t]{2}{*}{$\begin{array}{l}\text { Stabilisation level } \\
\mathrm{CO}_{2} \mathrm{e}\end{array}$} & \multirow[t]{2}{*}{$\begin{array}{l}\text { Date of global } \\
\text { peak emissions }\end{array}$} & \multirow[t]{2}{*}{$\begin{array}{l}\text { Global emissions } \\
\text { reduction rate } \\
\text { (\% per year) }\end{array}$} & \multicolumn{2}{|c|}{$\begin{array}{l}\text { Percentage reduction in emissions } \\
\text { below } \\
2005 \text { values }^{\mathrm{a}}\end{array}$} \\
\hline & & & 2050 & 2100 \\
\hline 450ppm & 2010 & 7.0 & 70 & 75 \\
\hline \multirow{4}{*}{$\begin{array}{l}500 \mathrm{ppm} \\
\text { (falling to } 450 \mathrm{ppm} \\
\text { in } 2150 \text { ) }\end{array}$} & 2020 & - & - & - \\
\hline & 2010 & 3.0 & 50 & 75 \\
\hline & 2020 & $4.0-6.0$ & $60-70$ & 75 \\
\hline & 2030 & $5.0^{b}-5.5^{c}$ & $50-60$ & $75-80$ \\
\hline \multirow{5}{*}{ 550ppm } & 2040 & - & - & - \\
\hline & 2015 & 1.0 & 25 & 50 \\
\hline & 2020 & $1.5-2.5$ & $25-30$ & $50-55$ \\
\hline & 2030 & $2.5-4.0$ & $25-30$ & $50-55$ \\
\hline & 2040 & $3.0-4.5^{\mathrm{d}}$ & $5-15$ & $50-60$ \\
\hline
\end{tabular}

Notes: a. 2005 emissions taken as $45 \mathrm{GtCO}_{2} \mathrm{e} / \mathrm{yr}$; b. overshoot to $520 \mathrm{ppm}$; c. overshoot to 550ppm; d. overshoot to $600 \mathrm{ppm}$. The symbol '-' indicates that stabilisation is not possible given the relevant assumption.

Source: Stern (2006a), p.200. 
(which tends to be a more expensive option than starting from scratch), and the adoption of relatively costly lowcarbon technologies.

Are such additional costs justifiable? This is a difficult question to answer. As Stern and his critics have repeatedly argued, there are large uncertainties surrounding the economics of climate change. What particular course of action is best, as judged in cost-benefit terms, depends on a large number of assumptions and estimates, all of which are open to question. Hence, in attempting to assess the likely marginal costs and benefits associated with different stabilisation targets one is faced with a huge potential margin of error. Having said this, the available evidence strongly suggests that the higher the stabilisation level, the greater the likely costs to the planet, and hence the greater the risks to human civilisation. Moreover, such costs can be expected to increase in a somewhat unpredictable and non-linear fashion, and many of the impacts are very likely to be serious and irreversible. A further relevant consideration is that there are bound to be significant cobenefits (many of which are difficult to quantify and place a dollar value on) associated with policy action to reduce emissions and improve land management practices. Such co-benefits include enhanced flood protection, improved water quality, greater energy efficiency, new technological breakthroughs, lower pollution levels, better health outcomes and an improved quality of life.

Additionally, adequate attention needs to be given to the precautionary principle. Under article 3.3 of the UNFCCC, the global community has agreed to

take precautionary measures to anticipate, prevent or minimize the causes of climate change and mitigate its adverse effects. Where there are threats of serious or irreversible damage, lack of full scientific certainty should not be used as a reason for postponing such measures, taking into account that policies and measures to deal with climate change should be cost-effective so as to ensure global benefits at the lowest possible cost.

Given the nature and magnitude of the risks if the global mean surface temperature rises by $2^{\circ} \mathrm{C}$ or more, there is surely a case, on precautionary grounds, for pursuing a stabilisation target as low as possible, even if this entails significant up-front costs (see Baer, 2007). There is equally a case for a substantial additional public investment in research and development with the aim of generating technologies that enable the pace of decarbonisation to be accelerated - thus making even lower targets technically feasible.

\section{Implications for New Zealand}

The New Zealand government has thus far refrained from endorsing any specific, long-term climate change target, whether in the form of a temperature cap (like the $\mathrm{EU})$ or a $\mathrm{CO}_{2}$ e stabilisation level. Nor has it committed itself to a particular long-term target with regard to GHG emission reductions, let alone specific milestones for achieving this target. Elsewhere, a growing number of countries and states/provinces within federal systems are making commitments of various kinds. For instance, Britain is not only a signatory to the EU temperature cap but has also set itself a target of reducing emissions by $60 \%$ below 1990 levels by 2050, while California is pursuing an even more ambitious target of $80 \%$ cuts by 2050. Within the EU, the environment commissioner, Stavros Dimas, has proposed a 30\% cut in emissions by 2020 , but this has yet to be agreed by member states.

Importantly, the prime minister, Helen Clark, spoke in late 2006 of the desirability of moving towards carbon neutrality (i.e. zero net emissions) as a long-term, national objective. Thus far, however, the government has been reluctant to associate itself with specific, medium-term targets, whether at an aggregate or sectoral level. Perhaps the only exception is the suggestion that the agricultural sector should consider the possibility of reducing methane and nitrous oxide emissions by at least $20 \%$ by 2012 (as compared with the business-asusual emission levels) (see Ministry of Agriculture and Forestry, 2006, p.24).

In considering the question of what targets New Zealand should endorse (in terms of both the nature of the targets and the timeframe for their achievement), it needs to be borne in mind that on a per capita basis this country's GHG emissions are relatively high (around 12th in the world). On equity grounds, it can be argued that countries with high per capita emissions should be obliged to make a disproportionately large contribution to the global effort to reduce emissions. Against this, almost $50 \%$ of New Zealand's emissions are from the agricultural sector (mostly in the form of methane from ruminant animals), and there is currently no technological solution available for reducing the bulk of these emissions (except via cuts in 
livestock numbers). Accordingly, it might be reasonable for New Zealand to argue that it cannot be expected to cut its agricultural emissions to the extent or at the speed of the reductions possible in the energy and transport sectors.

Nevertheless, there is a good case, based on the available scientific evidence, for New Zealand endorsing the EU temperature cap. If it did so, it would need to consider the implications in terms of a $\mathrm{CO}_{2}$ e stabilisation target and a related emissions pathway (both globally and nationally). In my view, New Zealand should seek international agreement on a $\mathrm{CO}_{2}$ e stabilisation target at the bottom end of the range suggested by the Stern Review (if not lower - at least as an ideal). On the issue of an emissions pathway, New Zealand should set itself appropriately high reduction targets for the energy and transport sectors, probably in the vicinity of $80-90 \%$ by 2050 , with appropriate milestones over the next four decades. On the issue of agricultural emissions, the government should commit significant additional funds to the challenge of reducing methane production by ruminants, as well as pursuing policies to reduce the rate of deforestation and encourage carbon farming. Above all, the government should take the lead in encouraging public discussion about the kind of long-term domestic targets (and related milestones) to which the country should commit itself, as well as the global targets on which it should seek international agreement. In doing so, every effort should be made to secure a broad, cross-party consensus on the key policy goals and the best means of achieving them.

\section{References}

Baer, P. (2007) 'The worth of an ice-sheet: A critique of the treatment of catastrophic impacts in the Stern Review', An EcoEquity discussion paper, www.ecoeuqity.org/docs/ WorthOfAnIceSheet.pdf

Chapman, R., J. Boston and M. Schwass (eds) (2006) Confronting Climate Change: critical issues for New Zealand, Wellington: Victoria University Press

Carter, R. et al., (2006) 'The Stern Review: A Dual Critique', World Economics, 7, 4, pp.165-232

Den Elzen, M. and M. Meinshausen (2006) 'Multigas emission pathways for meeting the $\mathrm{EU} 2{ }^{\circ} \mathrm{C}$ climate target', in H.J. Schellnhuber, W. Cramer, N. Nakicenovic, T. Wigley and G. Yohe (eds) Avoiding
Dangerous Climate Change, Cambridge: Cambridge University Press

Hatfield-Dodds, S. (2006) 'Reducing greenhouse emissions: interpreting the economic impacts', in R. Chapman, J. Boston and M. Schwass (eds) Confronting Climate Change: critical issues for New Zealand, Wellington: Victoria University Press

Intergovernmental Panel on Climate Change (2007) Climate Change 2007: The Physical Science Basis - Summary for Policy Makers Contribution of Working Group 1 to the Fourth Assessment Report of the Intergovernmental Panel on Climate Change, Geneva., IPCC Secretariat

Lawson, N. (2006) 'The economics and politics of climate change: an appeal to reason', lecture to the Centre of Policy Studies, London, 1 November

Lomborg, B. (2006) 'Stern Review: the dodgy numbers behind the latest warming scare', Wall Street Journal, 2 November

Meinshausen, M. (2006) 'What does a $2^{\circ} \mathrm{C}$ target mean for greenhouse gas concentrations?', in H.J. Schellnhuber et al. (eds) Avoiding Dangerous Climate Change, Cambridge: Cambridge University Press

Metz, B. and D. van Vuuren (2006) 'How, and at what costs, can low-level stabilization be achieved? - an overview', in H.J. Schellnhuber et al. (eds) Avoiding Dangerous Climate Change, Cambridge: Cambridge University Press

Ministry of Agriculture and Forestry (2006) Sustainable Land Management and Climate Change: options for a plan of action, Wellington

Murphy, J. et al. (2004) 'Quantification of modelling uncertainties in a large ensemble of climate change simulations', Nature, 430 , pp.768-72

Nordhaus, W. (2006) 'The Stern Review on the economics of climate change,' Yale University, 17 November, at http://nordhaus.econ.yale.edu/ SternReviewD2.pdf

Pittock, A.B. (2006) Climate Change: turning up the heat, London: Earthscan

Read, P. (2006) 'Carbon cycle management with biotic fixation and long-term sinks', in H.J. Schellnhuber et al. (eds) Avoiding Dangerous Climate Change, Cambridge: Cambridge University Press 
Schellnhuber, H.J., W. Cramer, N. Nakicenovic, T. Wigley and G. Yohe (eds) (2006) Avoiding Dangerous Climate Change, Cambridge: Cambridge University Press

Steffen, W. (2006) “Sleeping giants": surprises in the climate and earth system', in R. Chapman, J. Boston and M. Schwass (eds) Confronting Climate Change: critical issues for New Zealand, Wellington: Victoria University Press

Stern, N. (2006a) Stern Review on the Economics of Climate Change, London, October

Stern, N. (2006b) Stern Review - postscript, London, December

Tol, R. (2006) 'The Stern Review of the economics of climate change: a comment', Economic and Social Research Institute, Hamburg, Vrije and Carnegie Mellon Universities, at http://www.fnu.zmaw.de/fileadmin/fnufiles/reports/sternreview.pdf

Tol, R. and G. Yohe (2006) 'A Review of the Stern Review', World Economics, 7, 4.

Turley, C. (2006) 'Ocean acidification and its impacts', in R. Chapman, J. Boston and M. Schwass (eds) Confronting Climate Change: critical issues for New Zealand, Wellington: Victoria University Press

Wigley, T. and S. Raper (2001) 'Interpretation of high projections for global-mean warming', Science, 293, pp.451-4

Jonathan Boston is a Professor of Public Policy and Deputy Director of the Institute of Policy Studies at Victoria University of Wellington. He has authored or edited 20 books on policy-related issues, including Confronting Climate Change: Critical Issues for New Zealand (co-edited with Ralph Chapman and Margot Schwass, and published by Victoria University Press, 2006).

\section{CONCEPTUALISING THE BORDER}

An Institute of Policy Studies publication by Andrew Ladley and Nicola White

In a world interconnected by technology and transport, how a state manages its borders affects a very wide range of interests, including public health, the environment, local identity, security, trade, tourism and revenue.

Conceptualising the Border explores the simple connection between state sovereignty and border management. The conclusions suggested are relevant to the many policy questions that are confronting New Zealand and other states as they seek to both reduce and increase the barriers at their borders.

Published - October 2006

Format - A5 Paperback, pp 64

ISBN - 1-877347-13-2

Price $-\$ 27.00$ (incl P\&P within NZ)

To have a copy of Conceptualising the Border and an invoice sent to you please email, phone, fax or mail your order to:

Institute of Policy Studies

Victoria University of Wellington

Email ipos@vuw.ac.nz

Telephone +64 44635307

Fax +64 44637413

P0 Box 600, Wellington

New Zealand 